\title{
Triose phosphate-isomerase deficiency
}

INSERM

\section{Source}

INSERM. (1999). Orphanet: an online rare disease and orphan drug data base. Triose phosphate-isomerase deficiency. ORPHA:868

Triosephosphate isomerase (TPI) deficiency is a severe autosomal recessive inherited multisystem disorder of glycolytic metabolism characterized by hemolytic anemia and neurodegeneration. 